MATEC Web of Conferences 19, 01019 (2014)

DOI: $10.1051 /$ matecconf/ 20141901019

(C) Owned by the authors, published by EDP Sciences, 2014

\title{
Autothermal pyrolysis of peat in conditions of free movement in layer
}

\author{
Alexander V. Kazakova, Tatyana M. Plakhova ${ }^{1}$, and Roman I. Popov \\ National Research Tomsk Polytechnic University, 634050 Tomsk, Russia
}

\begin{abstract}
Modern trends of energy saving provide actuality of research. Ability to implement pyrolyze in autothermally mode was investigated. Method of research is a physical experiment. As a result of research are obtained: dependency diagram as the thickness layer of the angle inclination of working surface, dependency diagram as the fall ash of the angle inclination of working surface, dependency diagram as the moving rate of peat of the pyrolysis temperature with different inclinations of working surface.
\end{abstract}

\section{Introduction}

The relevance of the use of local low-grade fuels provides correspondence with current trends of the conservation of energy, in particular, the direction of implication in the fuel energy balance of lowgrade fuels and providing of electric and heat energy to areas of decentralized energy supply. Accordingly, development of power units, operating on local low-grade fuels, is timely as applied to energy-deficient areas with reserves of local fuels [1].

\section{Results and discussions}

Requirements on the minimum size of particles for exclusion the failure of through the grate are applied to burned fuels. Researches of the autothermal pyrolysis of peat in layer on the inclined surface investigated with a view to developing a method for combustion of peat without ashpit losses. The inclined surface allows to organize the thermal fuel reprocessing with simultaneous removal of the mineral part of [2-4].

During the decomposition of peat three boundaries of decomposing fuel clearly identified (Figure 1), the first boundary - the ash particles of decomposed fuel, second boundary - carbon residue and the third boundary - fresh not decomposed fuel.

According to the obtained experimental results by the approximation of coefficient reliability of approximation $\mathrm{R} 2=0.9811$ was plotted the dependency diagram as the thickness layer of the angle inclination of working surface (Figure 2).

The angle of inclination less than $25^{\circ}$ don't provides movement of layer in the process of pyrolysis, the angle is more than $40^{\circ}$ leads to freely rolling of the peat layer without pyrolysis. Thus, the operating range of the angles of processing is 25 to 40 degrees.

\footnotetext{
${ }^{\mathrm{a}}$ Corresponding author: kazakov@tpu.ru
} 


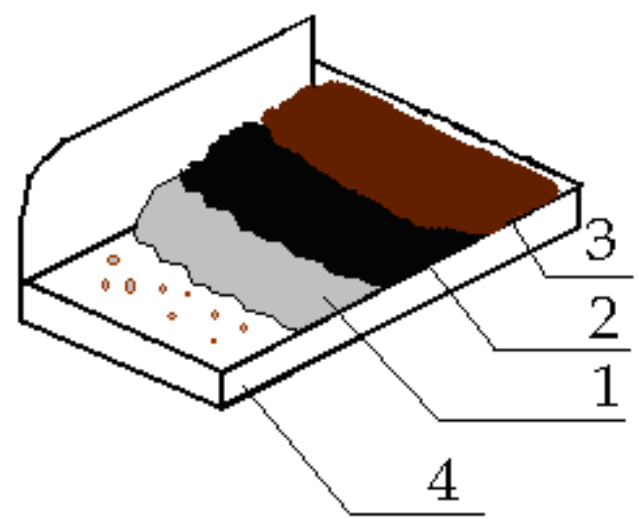

Figure 1. Zones of decomposing fuel: 1 - ash particles; 2 - carbon residue; 3 - fresh fuel; 4 - heater.

thickness layer , $\mathrm{mm}$

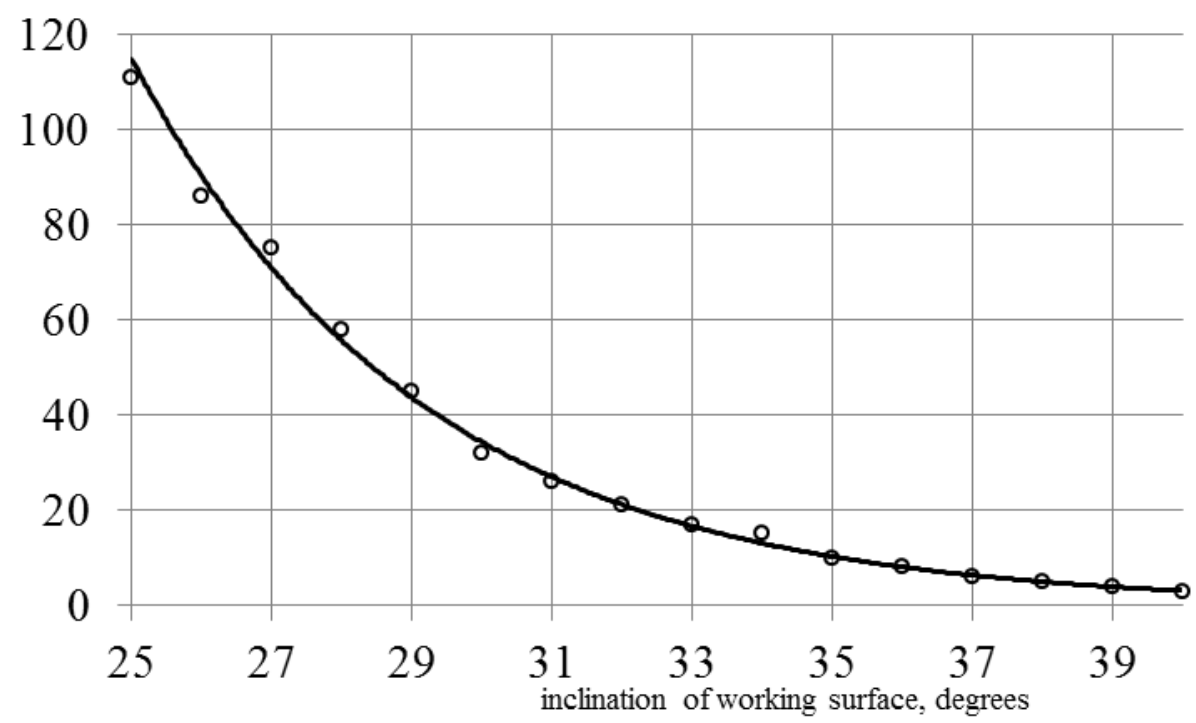

Figure 2. Dependency diagram as the thickness layer of the angle inclination of working surface.

The detected amount of fall ash in the process of pyrolysis, depending on the angle of inclination is shown in Figure 3.

Figure 3 shows that the removal of the mineral part on hundred percent is provided in the pyrolysis of the inclination angle of surface $37^{\circ}$. The maximum amount of not fall ash (24\%) accounts for the angle of $25^{\circ}$.

The nomogram (Figure 4), which characterizes the dependence of the moving rate of peat of the pyrolysis temperature with different inclinations of working surface, is plotted on the basis of additional experimental researches and taking into account the results in Figure. 2, 3.

Given the fact that the autothermal process of pyrolysis is carried out at temperatures of 250-300 ${ }^{\circ}$ $\mathrm{C}$ [5], it is apparently that the inclination angle of the surface should be in the range of 25-34 degrees (Figure 4). Accordingly, the moving rate of layer (pyrolysis rate) is in the range $0.1-2.5 \mathrm{~m} / \mathrm{h}$ of the layer thickness 18-110 mm (Figure 2). Thus, regime parameters of the process of pyrolysis for practical calculations can be defined by giving of required productivity. 
Amount of ash, \%

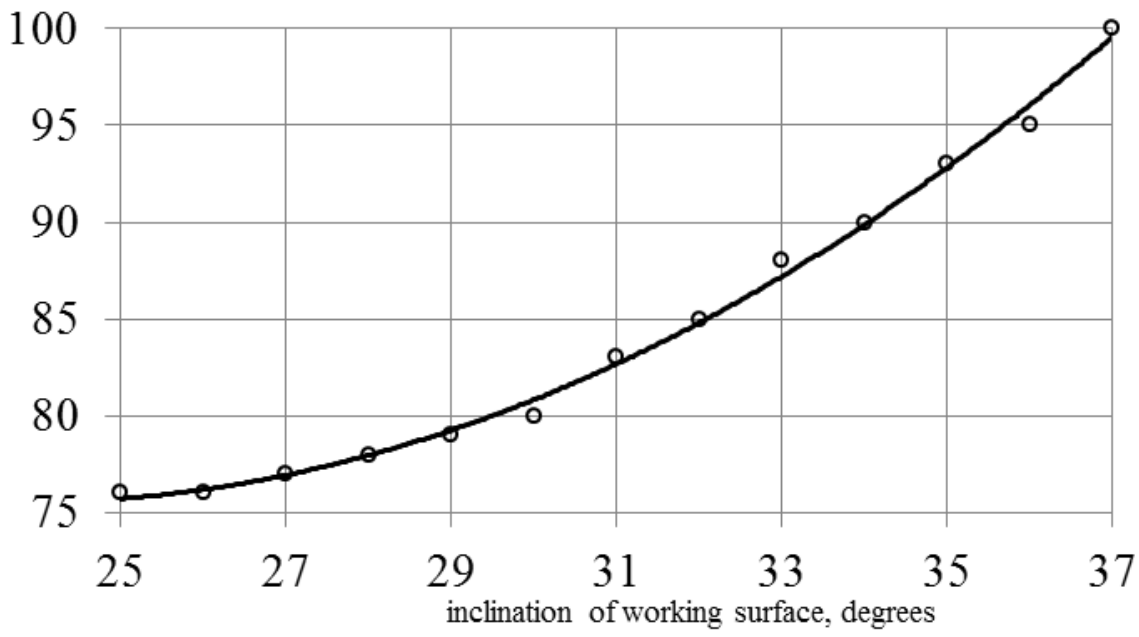

Figure 3. Dependency diagram as the fall ash of the angle inclination of working surface.

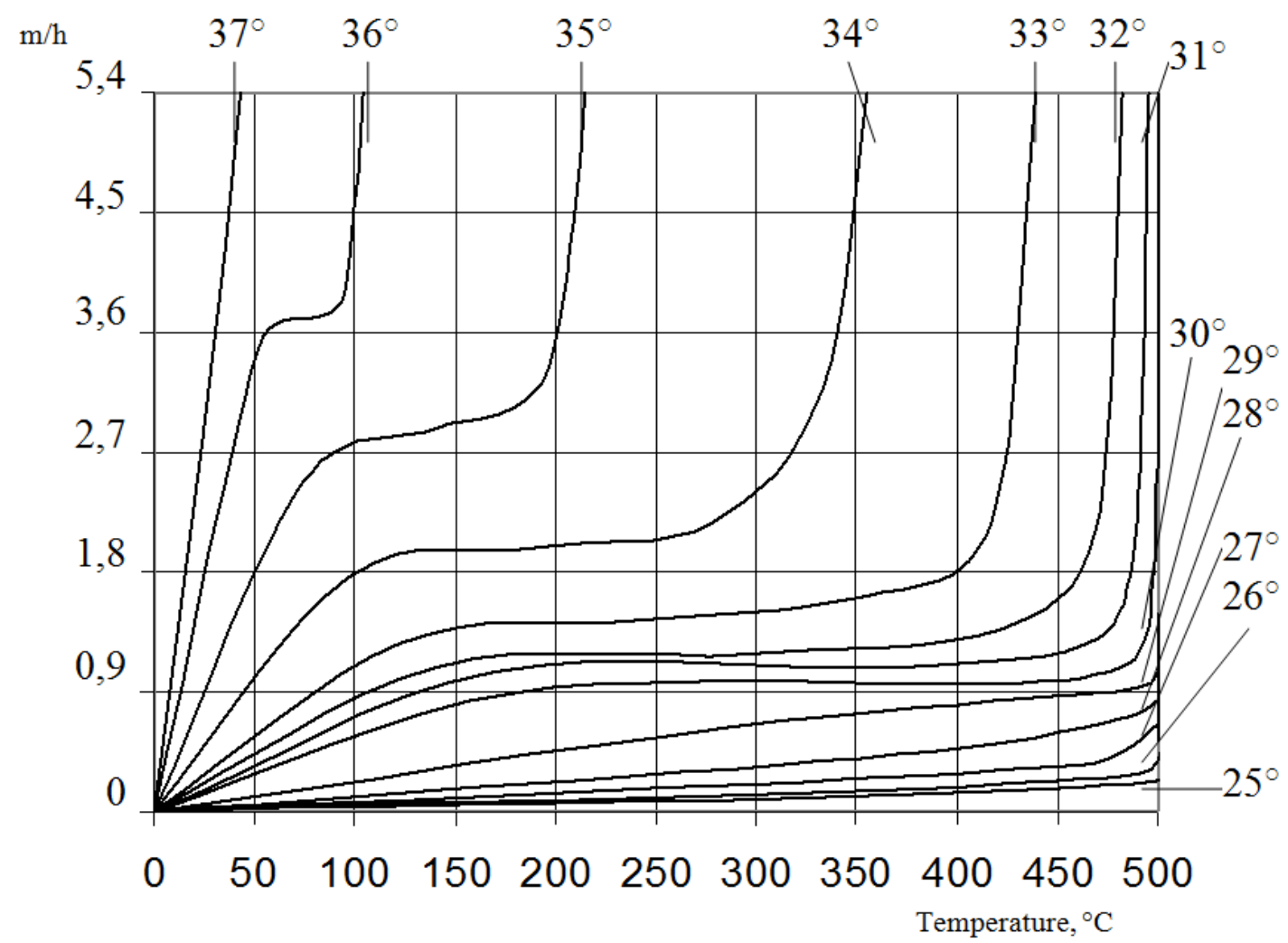

Figure 4. Dependency diagram as the moving rate of peat of the pyrolysis temperature with different inclinations of working surface. 


\section{Conclusions}

By analyzing the obtained experimental data, can be draw the following conclusions:

1. During the thermal decomposition of peat on inclined surface three boundaries of decomposing fuel clearly identified (Figure 1), the first boundary - the ash particles of decomposed fuel, second boundary - carbon residue and the third boundary - fresh not decomposed fuel.

2. Factors, which affected to ability of the ash of decomposed fuel is fallen on inclined work surface:

- Angle of the inclination of working surface;

- Height of the fuel layer;

- Temperature of pyrolysis.

3. Defined parameters (Figures 2-4) of peat pyrolysis on inclined surface at which it decomposes autothermally to removing of the ash residues. Installed dependences of the parameters: pyrolysis rate; temperature of process; angle of the inclination of surface; amount of removed ash residues; thickness of layer.

4. Results of the work are suitable for use at design of power units with layer combustion and gasification of low-grade fuels [6].

The reported study was partially supported by the Ministry of education and science of The Russian Federation (Government Order No. 13.948.2014/K).

\section{References}

1. Order of the Government of the Russian Federation of November 13, 2009 № 1715-r "Energy Strategy of Russia for the period up to 2030" [in Russian]

2. A. S. Zavorin, A. V. Kazakov, A.A. Makeev, S.V. Podorov, Thermal Engineering 57, 77 (2010)

3. R. B. Tabakaev, P. S. Gergelizhiu, A. V. Kazakov, A. S. Zavorin, IOP Conference Series: Materials Science and Engineering 66, 012052 (2014)

4. R. B. Tabakaev, A. V. Kazakov, A. S. Zavorin, Bulletin of the Tomsk Polytechnic University 323, 41 (2013) [in Russian]

5. A.V. Kazakov, Thermal conversion of low-grade fuels in relation to gas generating units: the Dissertation ... Candidate. tehn. Sciences, 158 (2002) [in Russian]

6. A.V. Kazakov, Low-tonnage conversion of low-grade fuels (technical solutions), 184 (2013) 